\title{
Twilight tropospheric and stratospheric photodissociation rates derived from balloon borne radiation measurements
}

\author{
A. Kylling ${ }^{1}$, T. Danielsen ${ }^{1}$, M. Blumthaler ${ }^{2}$, J. Schreder ${ }^{2}$, and B. Johnsen ${ }^{3}$ \\ ${ }^{1}$ Norwegian Institute for Air Research, Kjeller, Norway \\ ${ }^{2}$ Institute of Medical Physics, University of Innsbruck, Innsbruck, Austria \\ ${ }^{3}$ Norwegian Radiation Protection Authority, Oslo, Norway
}

Received: 4 March 2002 - Published in Atmos. Chem. Phys. Discuss.: 12 June 2002

Revised: 31 August 2002 - Accepted: 9 September 2002 - Published: 3 April 2003

\begin{abstract}
A new ligthweight multichannel moderate bandwidth filter instrument designed to be flown on balloons, is described. The instrument measures the radiation field within the short UV (center wavelength at $312 \mathrm{~nm}$ ) and long UV (center wavelength at $340 \mathrm{~nm}$ ). The angular and spectral characteristics of the instrument are discussed and the calibration procedure outlined. Measurements made during a stratospheric balloon flight at twilight conditions from GapTallard, France, are presented and compared with state-ofthe-art radiative transfer model simulations. The model simulations and the measurements agree within $\pm 10 \%( \pm 20 \%)$ for solar zenith angles smaller than $93^{\circ}\left(90^{\circ}\right)$ for the 340 (312) nm channel. Based on the model simulations of the measured radiation, actinic flux spectra are reconstructed. These are used to calculate various photodissociation rates.
\end{abstract}

\section{Introduction}

UV and visible radiation plays an important role for the photochemistry of the troposphere and the stratosphere. In spite of this in situ measurements of the UV radiation field in the troposphere and the stratosphere are relatively rare. Schiller et al. (1994) reported actinic flux measurements in the troposphere and stratosphere from a balloon platform. The instrument measured the actinic flux in a single wavelength interval, thus providing no spectral information. Recently airborne measurements have been made of the spectral actinic flux at selected altitudes using spectroradiometers, (see e.g. McElroy, 1995; McElroy et al., 1995; Shetter and Müller, 1999; Hofzumahaus et al., 2002). Gao et al. (2001) derived the $\mathrm{J}\left[\mathrm{NO}_{2}\right]$ in the lower stratosphere for low sun using in situ chemical measurements. Finally Bösch et al. (2001) have reported comparisons of measured proxy $\mathrm{J}\left[\mathrm{NO}_{2}\right]$ with model

Correspondence to: A. Kylling (arve.kylling@ nilu.no) simulations for large solar zenith angles in the troposphere and stratosphere.

Here measurements made by a new lightweight multichannel moderate bandwidth filter instrument, hereafter named NILU-CUBE, are reported. Measurements were made as the NILU-CUBE was flown on a balloon to an altitude of about $30 \mathrm{~km}$. The measurements are compared with model simulations and subsequent data analysis yields various photodissociation rates.

\section{Instrumentation}

The NILU-CUBE is a twelve channel moderate bandwidth filter instrument. It consists of six heads mounted on the faces of a cube, see Fig. 1. Each head measures the irradiance in two channels. The channels are centered at approximately 312 and $340 \mathrm{~nm}$ and have a full width at half maximum (FWHM) of approximately $10 \mathrm{~nm}$. In order to keep the weight and power consumption low, the instrument is not temperature stabilized. However, the instrument is very well insulated and the temperature is recorded for each of the six heads. Data are recorded every five seconds and stored in a separate logging unit.

During flight the NILU-CUBE is mounted such that one head faces upwards measuring the downwelling radiation. The opposite head measures the upwelling radiation while the remaining four heads point towards the horizon. As the balloon ascends the payload will rotate, hence the signal measured by the four heads pointed towards the horizon will vary considerably.

To check the NILU-CUBE before and after flying, a NILU-UV instrument was used. The NILU-UV is a six channel moderate bandwidth filter instrument. It measures the total (direct plus diffuse) downward irradiance at approximately $305,312,320,340$, and $380 \mathrm{~nm}$ with a FWHM of $10 \mathrm{~nm}$. In addition it has a channel covering photosyntheti- 


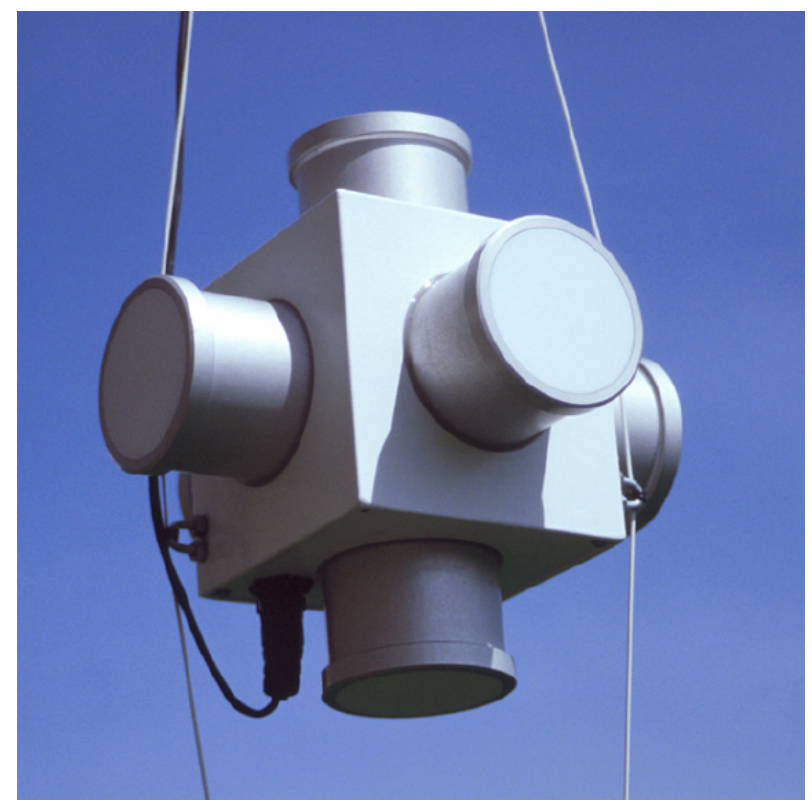

Fig. 1. The NILU-CUBE before being protected by styrofoam. The size is about $18 \mathrm{~cm}$ from head to head. The weight, including a separate data logging unit is less than $4 \mathrm{~kg}$.

cally active radiation (PAR) between $400-700 \mathrm{~nm}$. The 312 and $340 \mathrm{~nm}$ channels are identical on the NILU-UV and the NILU-CUBE except for the shape of the teflon diffusors on the respective instruments. The NILU-UV is temperature stabilized. It reported data every second to a computer. In addition to being used to check the stability of the NILU-CUBE before and after flying, the NILU-UV was used during the flight to monitor the radiation field at the surface. The clocks of the NILU-CUBE and the NILU-UV where synchronized using Global Position System (GPS) receivers prior to the flight.

\subsection{Angular response}

The radiation quantity of interest for photochemical applications is the actinic flux $F$ (Madronich, 1987)

$F(\lambda)=\int_{\phi} \int_{\theta} I(\lambda, \theta, \phi) \sin \theta d \theta d \phi$.

Here $I$ is the radiance in direction $\theta$ and $\phi$ at wavelength $\lambda$. The actinic flux represents the total number of photons incident at a point. Ideally an instrument for measurement of the actinic flux should have a relative angular response with unit response for all incoming directions, black line Fig. 2. Each head of the NILU-CUBE has a relative angular response similar to a cosine response, red line Fig. 2. By combining the signals from each head the response is similar to the blue line Fig. 2. Obviously if only the up- and downwelling irradiances are measured the radiation from the horizon is not accounted for. Combining the signal from all heads gives

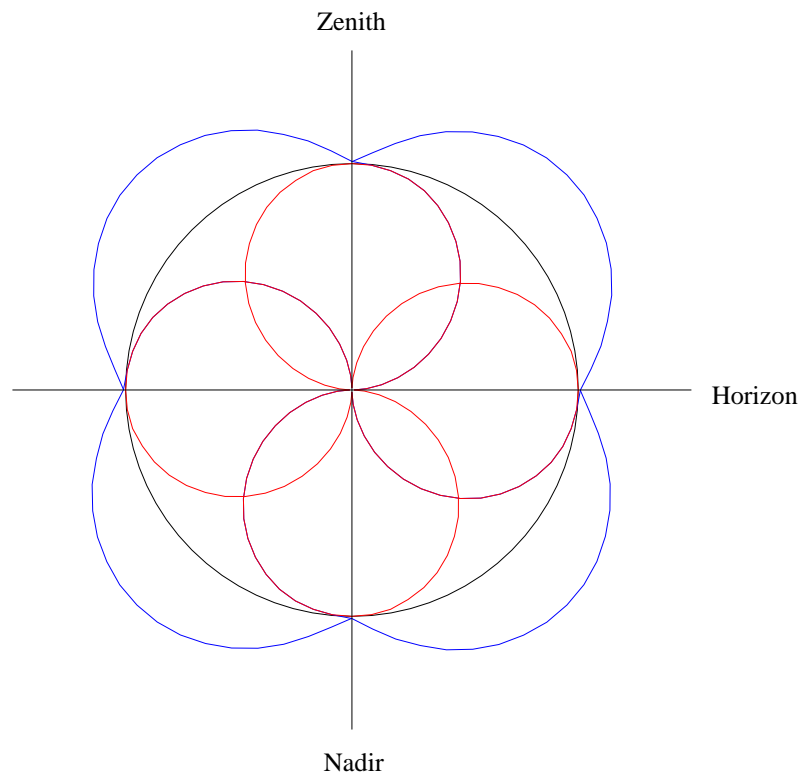

Fig. 2. Polar diagram of the relative angular response (black line) for an ideal actinic flux meter. (Red lines) The relative angular response of each of four NILU-CUBE heads if the instrument is viewed with one sensor pointing towards the reader. (Blue line) The effective relative angular response of the NILU-CUBE obtained by summing the individual responses (red lines) of the four heads.

an angular response that overestimates the actinic flux. The magnitude of the overestimate will depend on the behaviour of the radiation field which varies with wavelength, altitude, solar zenith angle, and atmospheric composition. This is further discussed below when correcting for the non-ideal angular response of the instrument.

While the angular response of the instrument does not have a unit response for each incoming direction, it is important that each head has similar angular responses. This was investigated in the laboratory by using a $1000 \mathrm{~W}$ lamp and rotary stage. In the left plot of Fig. 3 is shown the deviation from an ideal cosine response for each channel in each head for a given azimuth angle. The azimuth dependence was investigated for both channels in one head and is shown in the middle and right plot of Fig. 3. While the angular response is not a perfect cosine response the similarity of the various heads and channels is within 5\% which is sufficient for our purposes.

\subsection{Calibration}

The calibration procedure for moderate bandwidth filter instruments have been described by Dahlback (1996). The current $C_{i}$ measured by the instrument in channel $i$ when illuminated by spectral irradiance $E(\lambda)$ is

$C_{i}=k_{i} \int_{0}^{\infty} R_{i}(\lambda) E(\lambda) d \lambda$. 

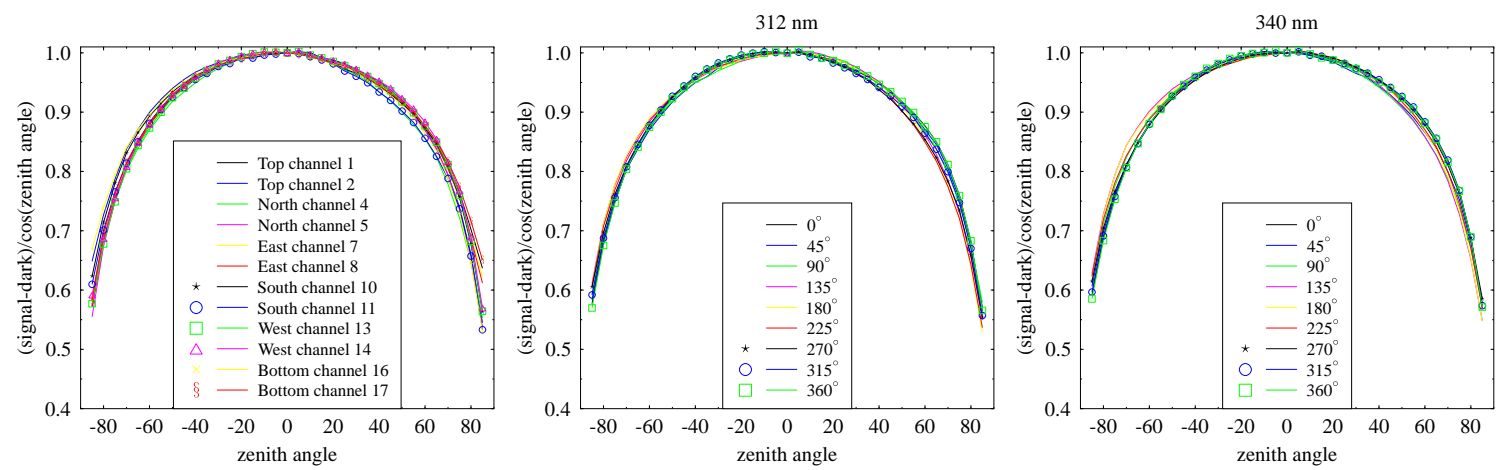

Fig. 3. (Left plot) The difference from an ideal cosine response for each channel for a fixed azimuth angle. (Middle plot) The same difference for the $312 \mathrm{~nm}$ channel of one head for various azimuth angles. (Right plot) Similar to the middle plot but for the $340 \mathrm{~nm}$ channel.

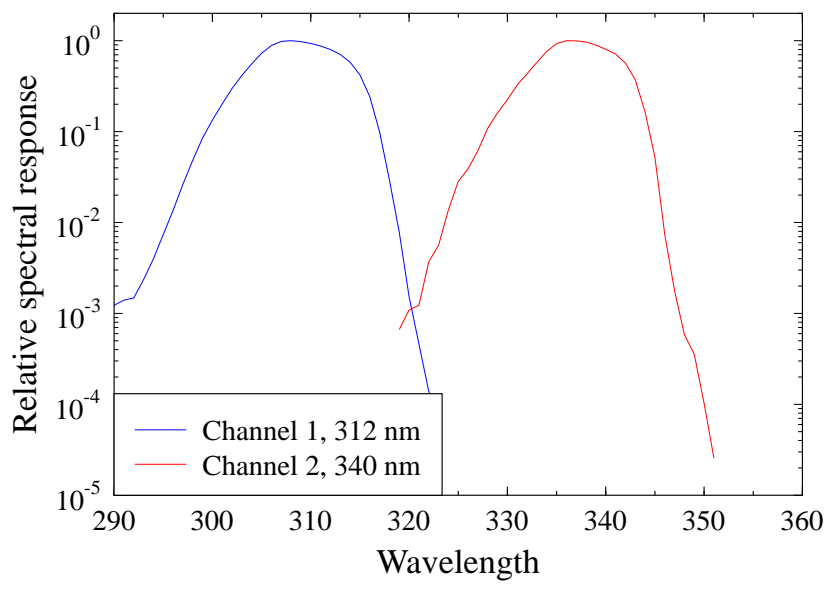

Fig. 4. The relative spectral response of the $312 \mathrm{~nm}$ and $340 \mathrm{~nm}$ channels.

Here $R_{i}$ is the relative responsivity of the channel. The calibration factors $k_{i}$ for each channel are determined by comparing measurements $E(\lambda)$ from a well characterized and high-quality spectroradiometer with simultaneous measurements $C_{i}$ from the filter instrument

$k_{i}=\frac{C_{i}}{\int_{0}^{\infty} R_{i}(\lambda) E(\lambda) d \lambda}$.

The relative spectral response of the NILU-CUBE was measured in the laboratory using a $1000 \mathrm{~W}$ Xe-lamp, a lightintensity controller and a calibrated reference radiometer. The relative spectral response is shown in Fig. 4. During the Photochemial Acticity and Solar Ultraviolet Radiation (ADMIRA) campaign in August 2000 at Nea Michaniona, Greece (Webb et al., 2002), the NILU-CUBE was collocated with a Bentham DTM300 scanning spectroradiometer. Following the procedure outlined above and detailed in Dahlback (1996), calibration factors were calculated for one of the heads. To minimize errors due to differences in the cosine responses, measurement made at local noon when the solar zenith angle was about $20^{\circ}$ was utilized. Due to the operational setup during the ADMIRA campaign it was not possible to rotate the NILU-CUBE to obtain calibration factors for the other heads. The calibration factors were transferred to the other heads using relative measurements made by each head against the NILU-UV prior to the flight.

The calibration factors depend on the spectral distribution of the irradiance. Model simulations were performed to investigate how the calibration factors change for the solar zenith angles and altitudes encountered during the flight. For the $340 \mathrm{~nm}$ channel the changes were less than $1 \%$ for all altitudes and solar zenith angles. For the $312 \mathrm{~nm}$ channel the changes were less then $3 \%$ for solar zenith angles smaller then $88^{\circ}$ or altitudes less than $19 \mathrm{~km}$. The change increased for larger solar zenith angles up to a maximum of about $18 \%$, giving too large measurements values, for solar zenith angles between $90^{\circ}$ and $94^{\circ}$. The measurements in the $312 \mathrm{~nm}$ channel have been corrected to account for these changes in the calibration factor.

Each head measures the irradiance. To convert from irradiance to actinic flux the contributions from all heads are summed as discussed in Sect.2.1. Finally the angular response correction is performed as explained below in Sect. 4.

\section{Measurements}

The balloon was launched from the airport of Gap-Tallard (44.457 ${ }^{\circ}$ N, 6.034 ${ }^{\circ}$ E, 618 m.a.s.1.), France, on 30 June 2000. The flight started at 17:48:50 UTC. It took about $90 \mathrm{~min}$. to reach the float altitude of approximately 30450 m.a.s.l. The balloon stayed at the float altitude for $28 \mathrm{~min}$. Altitude information was taken from GPS receivers. Comparison between the NILU-CUBE and the NILU-UV before and after flight revealed no detectable changes in the NILU-CUBE. The NILU-CUBE was last in the payload and about $100 \mathrm{~m}$ below the balloon. For all practical purposes the field of view 

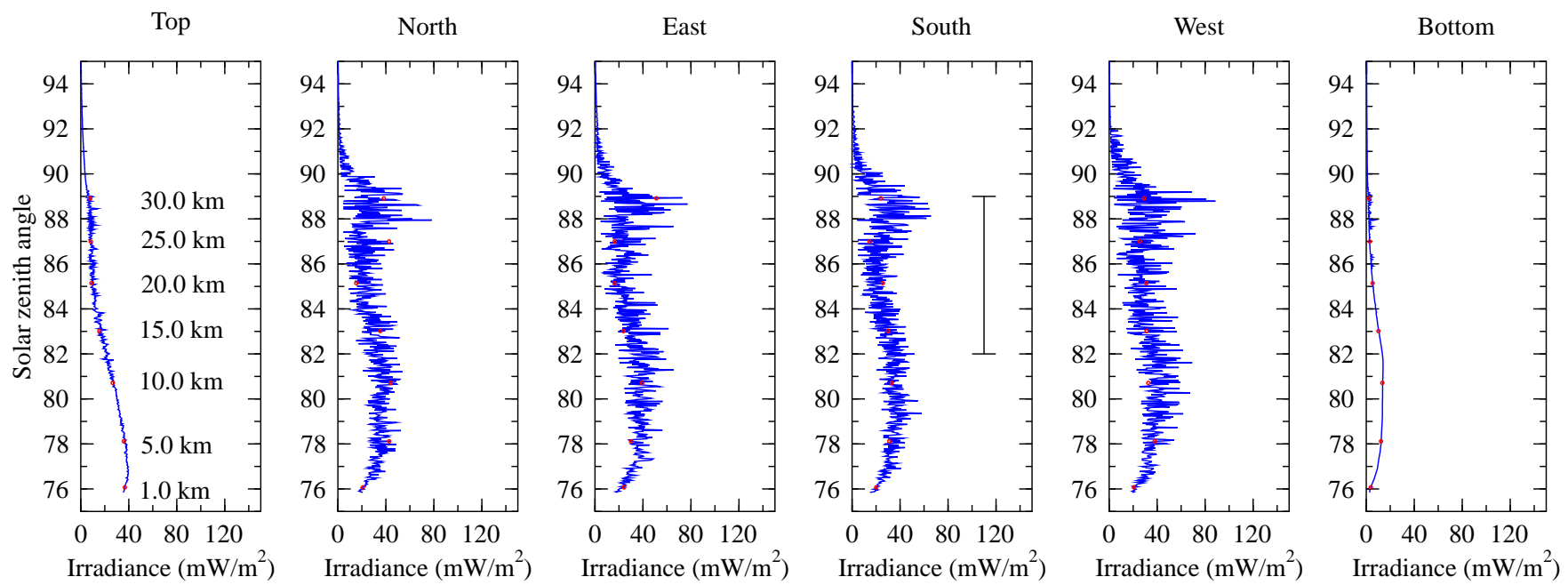

Fig. 5. The irradiances during the flight for the $312 \mathrm{~nm}$ channel as a function of solar zenith angle as measured by the various heads. The red dots give the measurements at the altitudes given in the panel for the top sensor. The balloon stayed at the float altitude for solar zenith angles between $89^{\circ}$ and $94^{\circ}$. See Fig. 7 for solar zenith angle versus altitude. The black vertical line for the south sensor panel indicates the altitude range for which absorption of radiation by the ozone layer is seen. See text for more comments.
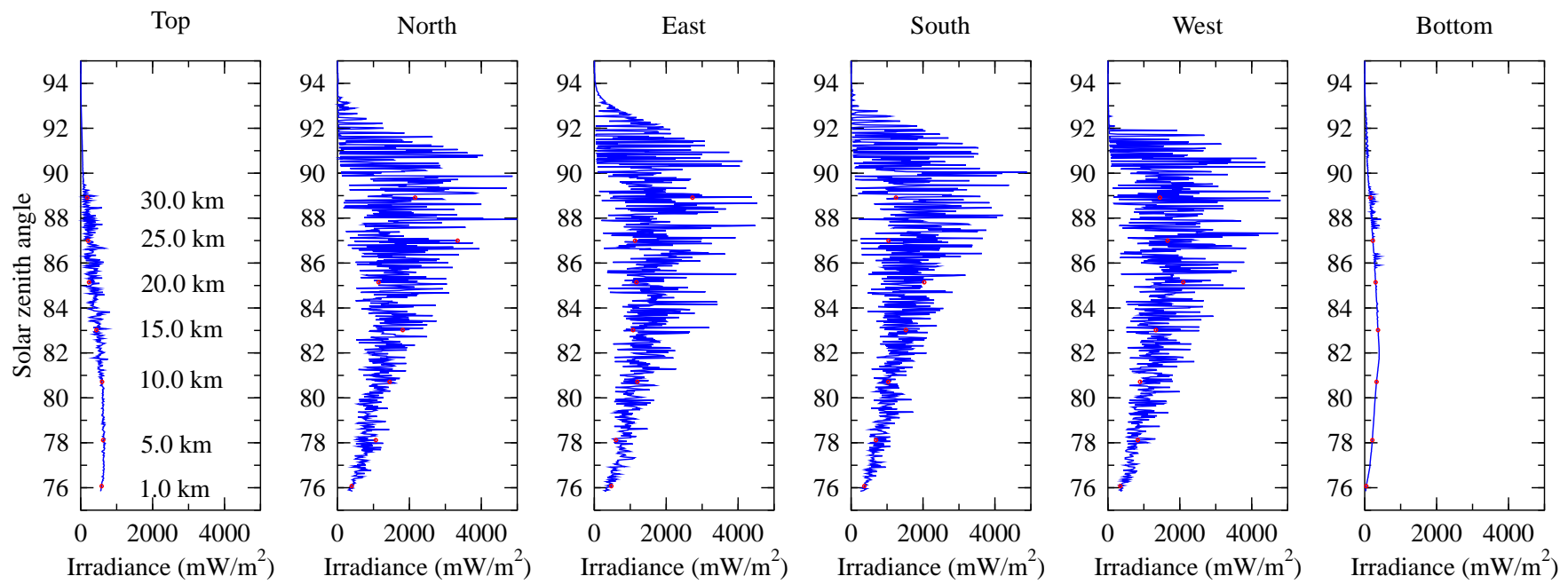

Fig. 6. Similar to Fig. 5, but for the $340 \mathrm{~nm}$ channel.

was thus more or less unobstructed for the measurement conditions, e.g. large solar zenith angles, during the flight.

In Figs. 5 and 6 are shown the irradiances measured by the different heads in the 312 and $340 \mathrm{~nm}$ channels respectively. The irradiances are shown as a function of the solar zenith angle. During the ascent the solar zenith angle increased from approximately $76^{\circ}$ to about $89^{\circ}$ when the float altitude was reached. At float altitude the solar zenith angle increased to $94^{\circ}$ before the descent started.

The magnitude of the signal in the $340 \mathrm{~nm}$ channel is significantly higher than the $312 \mathrm{~nm}$ channel. While the maximum in the $312 \mathrm{~nm}$ channel is about $80 \mathrm{~mW} / \mathrm{m}^{2}$ the maxi- mum in the $340 \mathrm{~nm}$ channel gets above $4000 \mathrm{~mW} / \mathrm{m}^{2}$. The extraterrestrial flux is approximately 1.45 larger at $340 \mathrm{~nm}$ than at $312 \mathrm{~nm}$. Hence, the major cause for the difference in magnitude between the two various channels is ozone absorption that affects the signal in the $312 \mathrm{~nm}$ channel but is negligible for the $340 \mathrm{~nm}$ channel. A clear ozone layer absorption signature is seen in the $312 \mathrm{~nm}$ channel in terms of the decline in the signal between solar zenith angles of $82-$ $86^{\circ}$ (corresponding to altitudes between approx. 12-23 km) and increase between $86-89^{\circ}$ (approx. 23-30 km). This altitude range is indicated by a black vertical line in the panel for the south sensor in Fig. 5. It is also noted that a sig- 

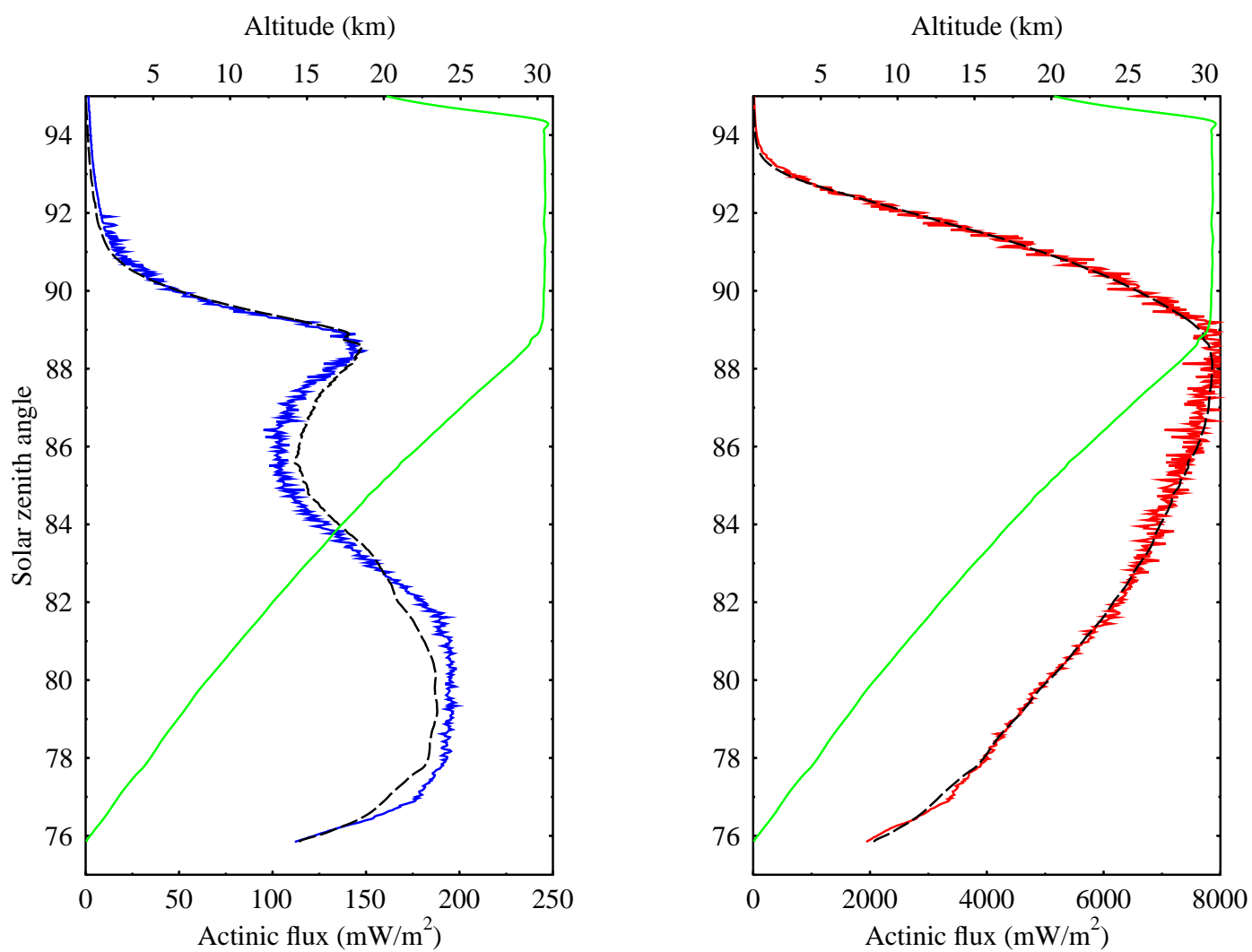

Fig. 7. The sum of the signal from all heads for each channel as a function of the solar zenith angle (blue line: $312 \mathrm{~nm}$, red line: $340 \mathrm{~nm}$ ). The green line is the altitude of the instrument. The black lines are model simulations of the measurements.

nificantly larger amount of radiation originates close to the horizon than from the zenith. This is obviously due to the large solar zenith angles and the altitude of the instrument. Nevertheless it underlines the importance of measuring the radiation from the horizon if the actinic flux is the radiation quantity of interest.

As the balloon ascends the signals in the various heads and channels vary considerably. The variations are largest in the horizontally oriented detectors that will be in and out of the direct beam from the sun as the instrument rotated. For the solar zenith angles encountered during the flight neither the balloon or other parts of the payload ever blocked the direct sun. The relative variation in the signal due to rotation is slightly larger in the $340 \mathrm{~nm}$ channel than the $312 \mathrm{~nm}$ channel. This is due to a somewhat larger proportion of the light being diffuse at $312 \mathrm{~nm}$ than at $340 \mathrm{~nm}$ because of the wavelength dependence of the Rayleigh scattering cross section. The ozone cross section is also larger at $312 \mathrm{~nm}$ than at $340 \mathrm{~nm}$. It is noted that the direct contribution to the total actinic flux between 25 and $30 \mathrm{~km}$ for the solar zenith angles encountered during the flight, can be up to $90 \%(80 \%)$ at $340(312) \mathrm{nm}$. For solar zenith angles larger than about $92^{\circ}$ $\left(93^{\circ}\right)$ the signal in the $312 \mathrm{~nm}(340 \mathrm{~nm})$ channel gets increasingly closer to the noise level and the measurements are thus less reliable.

The up (top) and down (bottom) pointing sensors are only marginally affected by the rotation of the payload. However, evidence of pendulum motion of the payload is seen in these signals. The downpointing sensor varies smoothly with altitude until the solar zenith angle gets large enough to let the sensor see the direct sun as the payload swings. Due to less scattered radiation at $340 \mathrm{~nm}$ the variations in both the down and upwelling irradiances are larger than at $312 \mathrm{~nm}$.

As the instrument rotates the horizontal heads mounted opposite of each other will experience maximums and minimums in the radiation field. By combining the signals from all heads, see Fig. 7, the large variations in Figs. 5 and 6 diminish, hence facilitating further analysis. In the summed signales a clear distinct ozone layer signal is still seen in the $312 \mathrm{~nm}$ channel. To further investigate the behaviour of the measured radiation, model simulations were performed.

\section{Simulations}

The measurements were simulated by the uvspec model from the libRadtran package (http://www.libradtran.org). The radiative transfer equation was solved by the discrete ordinate algorithm of Stamnes et al. (1988) operating in 16 streams 


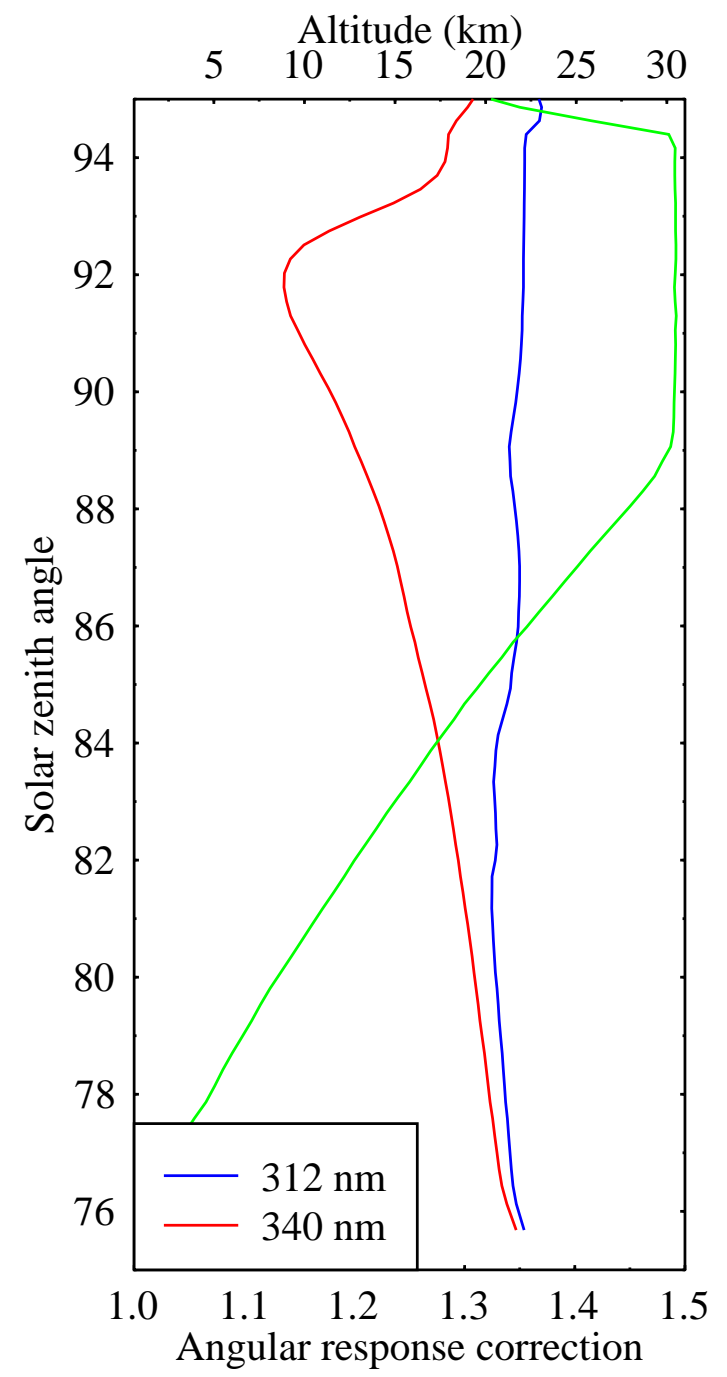

Fig. 8. The angular response correction factors for the two channels as a function of solar zenith angle. The green line is the altitude of the instrument.

mode with spherical correction as described by Dahlback and Stamnes (1991). The radiative transfer model has compared well with surface UV irradiance measurements (Mayer et al., 1997; Kylling et al., 1998) and airborne troposheric actinic flux measurements (Hofzumahaus et al., 2002). Input to the model are the ozone and temperature profiles, surface albedo and altitude and solar zenith angle information. The atmosphere was divided into 98 layers with about $0.4 \mathrm{~km}$ resolution between the surface and $31 \mathrm{~km}$, then $2.5 \mathrm{~km}$ resolution up to $50 \mathrm{~km}$ and $5 \mathrm{~km}$ above.

Ozone and temperature profiles were taken from an ozone sonde launched from Observatoire Haute Provence, (OHP), $100 \mathrm{~km}$ to the south of Gap-Tallard, on 28 June. The ozone column estimate from the sonde data was 303 DU. For 30 June the Earth Probe/Total Ozone Mapping Spectrometer (EP-TOMS) estimated the total ozone column to be 315 DU.
However better agreement between the model and measurement was found using the slightly lower value of $283 \mathrm{DU}$. Data from EP-TOMS between 28-30 June indicates that the ozone field was relatively stable during this period. Hence, the profile from 28 June is expected to be representative for the conditions on 30 June. The ozone cross section was taken from Bass and Paur (1985). The ground albedo was set to 0.05 which is representative for the type of surfaces around Gap-Tallard (Feister and Grewe, 1995). The Atlas 3 extraterrestrial spectrum shifted to air wavelengths (M. E. VanHoosier, personal communication, 1996) was used and the Earth-Sun distance was corrected for.

No information about aerosols composition and concentration was available for the flight. As the measurements were made during a volcanically quiescent period in the stratosphere it is justifiable to use a standard background aerosol model. The aerosol extinction profile was taken from the spring-summer background aerosol profile of Shettle (1989). The surface visibility, which for this aerosol model affects the aerosol up to altitudes of $2 \mathrm{~km}$, was set to $50 \mathrm{~km}$. The Henyey-Greenstein phase function was used with asymmetry factor from the above spring-summer background aerosol model. Sensitivity studies with higher aerosol loadings representative for high and extreme stratospheric aerosol conditions gave poor agreement between the model simulations and the measurements.

As noted in Sect. 2.1, combining the signal from all heads will overestimate the actinic flux. To quantify this overestimate the radiance fields were calculated for 312 and $340 \mathrm{~nm}$ for all the altitudes and solar zenith angles for which measurements were made. These radiance fields were integrated using the measured angular response of the NILU-CUBE to yield a simulated NILU-CUBE signal. This simulated signal was ratioed with the actinic flux from the same simulations. This ratio is termed the angular response correction factor and is the number with which the NILU-CUBE measurements must be divided to get the actinic flux. The angular response correction factor is shown in Fig. 8. The angular response factor is nearly constant for the $312 \mathrm{~nm}$ channel while it varies considerably with altitude for the $340 \mathrm{~nm}$ channel. This is due to the radiation field being more isotropic at $312 \mathrm{~nm}$ than at $340 \mathrm{~nm}$. The NILU-CUBE data shown in Figs. 7 and 9 have been corrected using the angular response correction factors shown in Fig. 8.

The NILU-CUBE reports data values every $5 \mathrm{~s}$ which corresponds to an altitude resolution of about $50 \mathrm{~m}$. For each altitude an actinic flux spectrum was calculated and convolved with the spectral response for each channel. The resulting simulated actinic fluxes are shown as black lines in Fig. 7.

The model/measurement ratio as a function of the solar zenith angle is shown in Fig. 9. For solar zenith angles up to $90^{\circ}$ the simulations are within $20 \%$ of the measurements for the $312 \mathrm{~nm}$ channel. For the $340 \mathrm{~nm}$ channel the simulations and measurements agree to better than $10 \%$ for solar zenith angles up to $93^{\circ}$. Considering the large solar zenith angles, 
$312 \mathrm{~nm}$

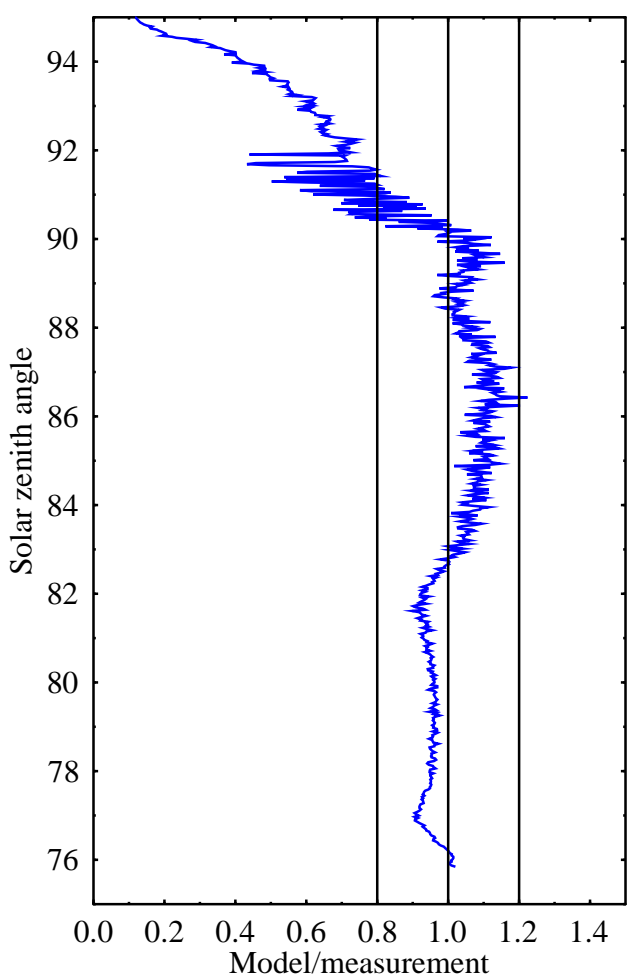

$340 \mathrm{~nm}$

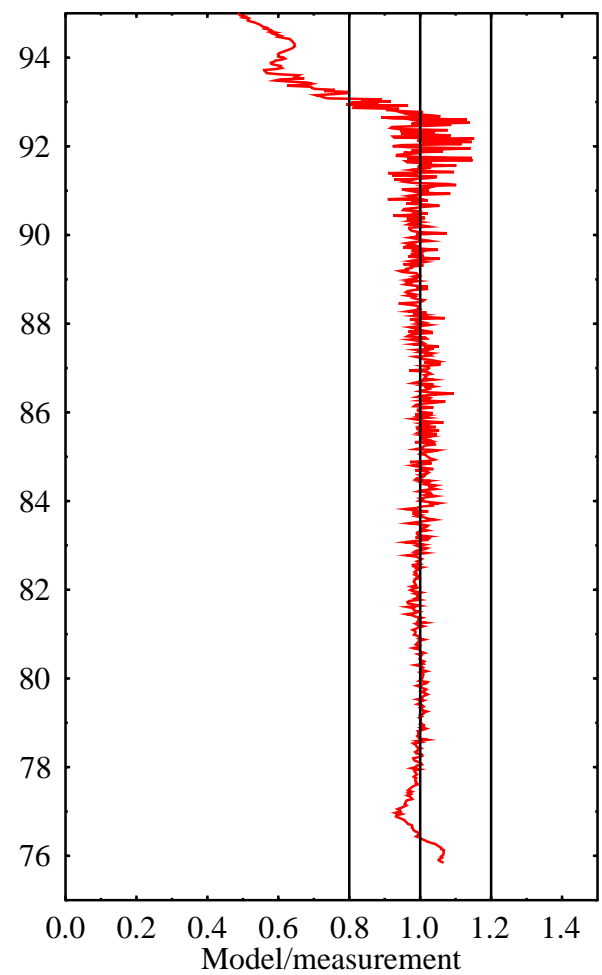

Fig. 9. The ratio of simulations versus measurements as a function of the solar zenith angle for the two channels.

the associated uncertainties in the correctness of the pseudospherical approximation used for the model simulations, the uncertainties in the aerosol optical properties, and the measurement uncertainties, the results gives confidence in both the behaviour of the instrument and the model simulation.

Somewhat larger differences are seen between the simulations and the measurements in the $312 \mathrm{~nm}$ channel compared to the $340 \mathrm{~nm}$. These may be attributed to uncertainties in the ozone profile with respect to the actual profile during the flight.

\section{Photodissociation rates}

Dahlback (1996) showed that it was possible to reconstruct UV irradiance spectra based on the measured total ozone column and the measured effective cloud optical depth. As shown by e.g. Webb etal. (2002) the ratio of actinic flux spectra to irradiance spectra depend on wavelength, solar zenith angle and aerosol amount. However, the same spectral lines are present in both irradiance and actinic flux spectra. Above the radiation measured in the 312 and $340 \mathrm{~nm}$ channels by the NILU-CUBE was simulated by a radiative transfer model. The most important input for the simulation was the total ozone column, the ozone profile, solar zenith angle and altitude information. The same input was used to calcu- late the actinic flux at other wavelengths. Thus, effectively an actinic flux spectrum was reconstructed from the measurements made at two wavelengths. While this approach has not been validated by simultaneous measurements by the NILU-CUBE and a spectroradiometer measuring the actinic flux, the model has been validated thoroughly against surface irradiance measurements (Mayer et al., 1997; Kylling et al., 1998) and airborne actinic flux measurements (Hofzumahaus et al., 2002). From these measurement/model comparisons there are no indications that if the model is able to reproduce the measurements at one wavelength it will fail at other wavelengths.

The reconstructed actinic flux spectra may be used together with the appropriate cross sections and quantum yields to calculate various photodissociation rates of interest. Examples of the $\mathrm{J}\left[\mathrm{NO}_{2}\right]$ and $\mathrm{J}\left[\mathrm{O}\left({ }^{1} \mathrm{D}\right)\right]$ photodissociation rates as estimated from the NILU-CUBE measurements are provided in Fig. 10. The ozone cross section and quantum yields used to calculate $\mathrm{J}\left[\mathrm{O}\left({ }^{1} \mathrm{D}\right)\right]$ were taken from Bass and Paur (1985) and Matsumi et al. (2002) respectively, while the $\mathrm{NO}_{2}$ cross section and quantum yields were taken from Davidson et al. (1988) and DeMore et al. (1994) respectively. The accuracy of the $\mathrm{NO}_{2}$ cross sections are estimated to be $\pm 5 \%$ (Davidson et al., 1988). Calculation of $\mathrm{J}\left[\mathrm{NO}_{2}\right]$ with the $\mathrm{NO}_{2}$ cross section of Schneider et al. (1987) are about 4-5\% smaller then if using Davidson et al. (1988). The most re- 

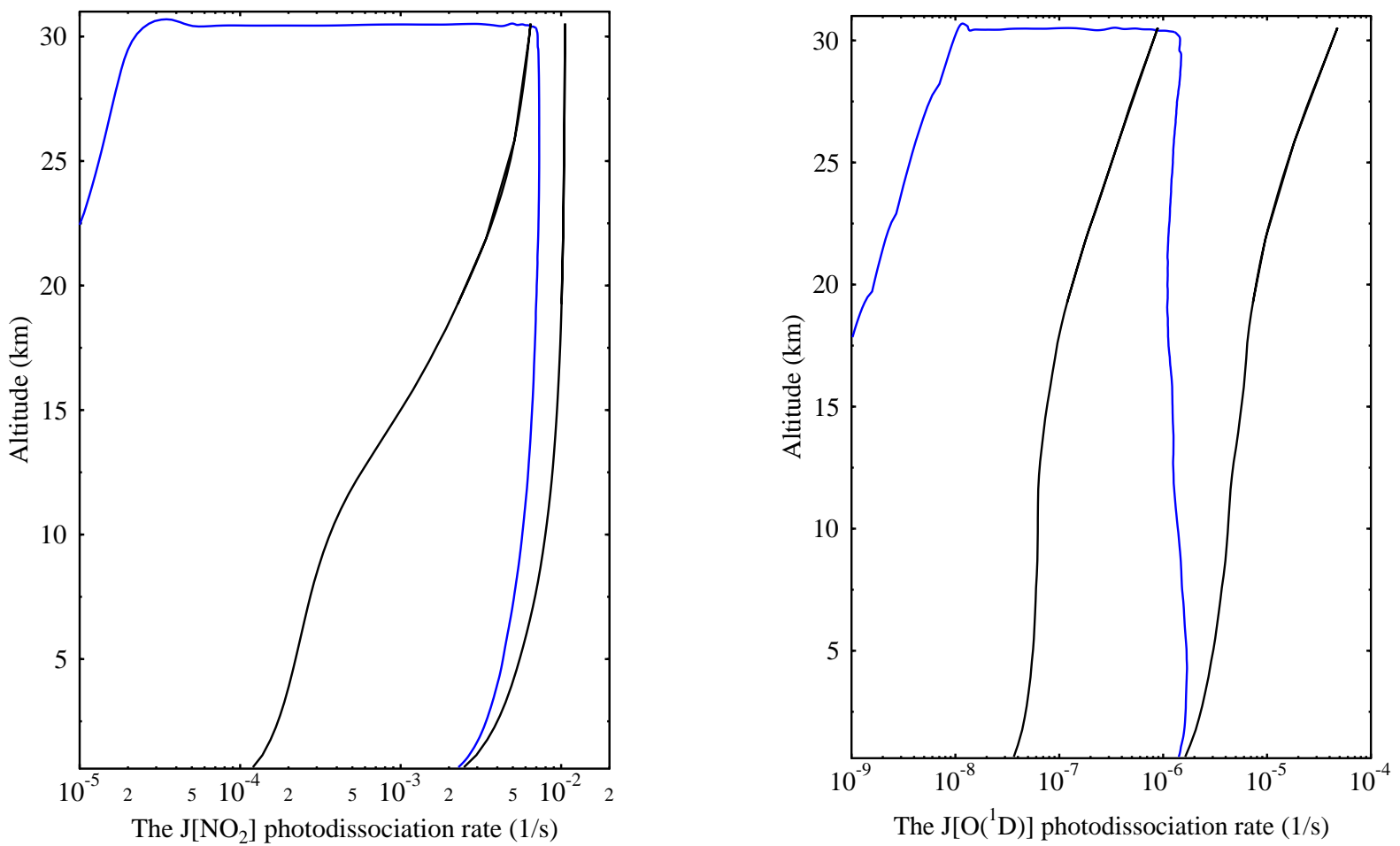

Fig. 10. The $J\left[\mathrm{NO}_{2}\right]$ and $J\left[\mathrm{O}\left({ }^{1} \mathrm{D}\right)\right]$ photodissociation rates as estimated from the NILU-CUBE measurements (blue lines). Also shown are the same photodissociation rates, but for constant solar zenith angles of $75^{\circ}$ (right black lines) and $90^{\circ}$ (left black lines).

cent recommendations of the "tail" in the $\mathrm{O}\left({ }^{1} \mathrm{D}\right)$ quantum yield have been given by Matsumi etal. (2002). The parameterization of Matsumi et al. (2002) give 15-18\% larger $\mathrm{J}\left[\mathrm{O}\left({ }^{1} \mathrm{D}\right)\right]$ for solar zenith angles betwen $82^{\circ}$ and $92^{\circ}$ than using the $\mathrm{O}\left({ }^{1} \mathrm{D}\right)$ quantum yield of Talukdar et al. (1998). This is larger then the differences $(<2 \%)$ reported by Matsumi et al. (2002), however, they reported differences for the surface while the differences reported here occur at altitudes above $13 \mathrm{~km}$.

As opposed to earlier figures the photodissociation rates are shown as a function of altitude in Fig. 10. The figure includes data from the ascent, the float altitude of approximately $30 \mathrm{~km}$ and the descent. It must be kept in mind that as the balloon ascends the solar zenith angle increases. Hence the blue lines in Fig. 10 also include solar zenith angle variations. The black lines in Fig. 10 are examples of instantaneous photodissociation rate profiles calculated with the same input data for solar zenith angles of $75^{\circ}$ and $90^{\circ}$.

\section{Conclusions}

A new lightweight multichannel moderate bandwidth filter instrument has been flown on a balloon in the troposphere and stratosphere for solar zenith angles between $76-95^{\circ}$. After correcting for the angular response the instrument effectively measures the actinic flux at two channels centered at
312 and $340 \mathrm{~nm}$ with a bandwidth at FWHM of approximately $10 \mathrm{~nm}$. The measurements have been compared with a state-of-the-art radiative transfer model. Agreement within $\pm 10 \%( \pm 20 \%)$ are found for solar zenith angles smaller than $93^{\circ}\left(90^{\circ}\right)$ for the $340(312) \mathrm{nm}$ channel. The agreement between the model and the measurements indicates that the so-called pseudo-spherical approximation is well suited to calculate the actinic flux at large solar zenith angles. And at least for cloudless sky conditions the present results supports the conclusions of Bösch et al. (2001) that uncertainties in UV and visible actinic fluxes is not a likely factor that may explain the discrepanices between model and measured stratospheric $\mathrm{NO}_{2}$ at large solar zenith angles.

From the simulations actinic flux spectra are reconstructed from which various photodissociation rates are calculated. Such photodissociation rates are important for testing and verification of radiation schemes used in chemistry models.

Further development of the instrument include better angular response of the input opitcs and comparison of reconstructed actinic flux spectra with measured actinic flux spectra. To improve the agreement between simulations and measurements, simultaneous measurements are needed of the ozone profile and the aerosol optical properties.

Acknowledgements. This work was performed within the COZUV project funded by the Norwegian Research Council. The authors are grateful to F. Goutail for making it possible for us to take part in the flight and for providing us with ozone and altitude informa- 
tion. The excellent support by the CNES ballon team is also kindly acknowledged. The ADMIRA campaign was part of the ADMIRA project funded by the European Commission (contract EVK2-199900167).

\section{References}

Bass, A. M. and Paur, R. J.: The ultraviolet cross-section of ozone, I, The measurements, in Atmospheric Ozone: Proceedings of the Quadrennial Ozone Symposium, edited by C. S. Zerefos and A. Ghazi, pp. 601-606, D. Reidel, Norwell, Mass., 1985.

Bösch, H., Camy-Peyret, C., Chipperfield, M., Fitzenberger, R., Harder, H., Schiller, C., Schneider, M., Trautmann, T., and Pfeilsticker, K.: Comparison of measured and modeled stratospheric UV/visible actinic fluxes at large solar zenith angles, Geophys. Res. Lett., 28, 1179-1182, 2001.

Dahlback, A.: Measurements of biologically effective UV doses, total ozone abundances, and cloud effects with multichannel, moderate bandwidth filter instruments, Appl. Opt., 35, 6514-6521, 1996.

Dahlback, A. and Stamnes, K.: A new spherical model for computing the radiation field available for photolysis and heating at twilight, Planet. Space Sci., 39, 671-683, 1991.

Davidson, J.A., Cantrell, C.A., McDaniel, A.H., Shetter, R.E., Madronich, S., and Calvert, J. G.: Visible-Ultraviolet absorption cross section for $\mathrm{NO}_{2}$ as a function of temperature, J. Geophys. Res., 93, 7105-7112, 1988.

DeMore, W. B., Sander, S.P., Golden, D. M., Hampson, R. F., Kurylo, M. J., Howard, C. J., Ravishankara, A. R., Kolb, C. E., and Molina, M. J.: Chemical kinetics and photochemical data for use in stratospheric modeling. Evaluation number 11, JPL publication 94-26, 1994.

Feister, U. and Grewe, R.: Spectral albedo measurements in the UV and visible region over different types of surfaces, Photochem. Photobiol., 62, 736-744, 1995.

Gao, R. S., Del Negro, L. A., Swartz, W. H., Salawitch, R. J., Lloyd, S. A., Profitt, M.H., Fahey, D.W., Donnelly, S.G., Neumann, J. A., Stimpfle, R. M., and Bui, T. P.: $\mathrm{J}_{\mathrm{NO}_{2}}$ at high solar zenith angles in the lower stratosphere, Geophys. Res. Lett., 28, 24052408, 2001.

Hofzumahaus, A., Kraus, A., Kylling, A., and Zerefos, C.: Solar actinic radiation $(280-420 \mathrm{~nm})$ in the cloud-free troposphere between ground and $12 \mathrm{~km}$ altitude: Measurements and model results, J. Geophys. Res., 107, 10.1029/2001JD900142, 2002.

Kylling, A., Bais, A. F., Blumthaler, M., Schreder, J., Zerefos, C. S., and Kosmidis, E.: The effect of aerosols on solar UV irradiances during the Photochemical Activity and Solar Ultraviolet Radiation campaign, J. Geophys. Res., 103, 26 051-26 060, 1998.

Madronich, S.: Photodissociation in the atmosphere 1. Actinic flux and the effects of ground reflections and clouds, J. Geophys. Res., 92, 9740-9752, 1987.

Matsumi, Y., Comes, F. J., Hancock, G., Hofzumahaus, A., Hyes, A. J., Kawasaki, M., and Ravishankara, A. R.: Quantum yields for production of $\mathrm{O}\left({ }^{1} D\right)$ in the ultraviolet photolysis of ozone: Recommendation based on evaluation of laboratory data, J. Geophys. Res., 107, 10.1029/2001JD000510, 2002.

Mayer, B., Seckmeyer, G., and Kylling, A.: Systematic long-term comparison of spectral UV measurements and UVSPEC modeling results, J. Geophys. Res., 102, 8755-8767, 1997.

McElroy, C. T.: A spectroradiometer for the measurement of direct and scattered solar irradiance from on-board the NASA ER-2 high-altitude research aircraft, Geophys. Res. Lett., 22, 13611364, 1995.

McElroy, C. T., Midwinter, C., Barton, D. V., and Hall, R. B.: A comparison of $\mathrm{J}$-values from the composition and photodissociative flux meausurement with model calculations, Geophys. Res. Lett., 22, 1365-1368, 1995.

Schiller, C., Hofzumahaus, A., Müller, M., Klein, E., Röth, E.-P., and Schmidt, U.: Ultraviolet actinic flux in the stratosphere: An overview of balloon-borne measurements during EASOE, 1991/92, Geophys. Res. Lett., 21, 1239-1242, 1994.

Schneider, W., Moortgat, G. K., Tyndall, G. S., and Burrows, J. P.: Absorption cross section of $\mathrm{NO}_{2}$ in the UV and visible region (200-700 nm) at $298 \mathrm{~K}$, Photochem. Photobiol., 40, 195-217, 1987.

Shetter, R.E. and Müller, M.: Photolysis frequency measurements using actinic flux spectroradiometry during the PEM-Tropics mission: instrumentation description and some results, J. Geophys. Res., 104, 5647-5661, 1999.

Shettle, E. P.: Models of aerosols, clouds and precipitation for atmospheric propagation studies, paper presented at Conference on Atmospheric Propagation in the UV, Visible, IR and MM-Region and Related System Aspects, NATO Adv. Group for Aerosp. Res. and Dev., Copenhagen, 1989.

Stamnes, K., Tsay, S.-C., Wiscombe, W., and Jayaweera, K.: Numerically stable algorithm for discrete-ordinate-method radiative transfer in multiple scattering and emitting layered media, Appl. Opt., 27, 2502-2509, 1988.

Talukdar, R. K., Longfellow, C. A., Gilles, M. K., and Ravishankara, A. R.: Quantum yields of $\mathrm{O}\left({ }^{1} \mathrm{D}\right)$ in the photolysis of ozone between 289 and $329 \mathrm{~nm}$ as a function of temperature, Geophys. Res. Lett., 25, 143-146, 1998.

Webb, A. R., Bais, A. F., Blumthaler, M., Gobbi, G.-P., Kylling, A., Schmitt, R., Thiel, S., Barnaba, F., Danielsen, T., Junkermann, W., Kazantzidis, A., Kelly, P., Kift, R., Liberti, G. L., Misslbeck, M., Schallhart, B., Schreder, J., and Topaloglou, C.: Measuring spectral actinic flux and irradiance: Experimental results from the ADMIRA (Actinic Flux Determination from Measurements of Irradiance), J. Atm. Ocean Technol., 19, 1049-1062, 2002. 